\title{
Development of Waterproof Ultrasonic Motor
}

\author{
Shigeki Toyama and Uichi Nishizawa
}

\begin{abstract}
The authors have developed a multi degree of freedom piezoelectric actuator that has Translational and Rotational motions in one joint (TR motor). Because the motor has the advantages such as simple structure and excellent controllability, it has high potentials for wide use in non-industrial application. The authors will apply it to outdoor use, especially, use in water. In this paper, the authors have applied insulating processing to the piezoelectric element for waterproof and designed an optimal shape of it for driving in water. The authors have succeeded in driving TR motor in water.
\end{abstract}

Index Terms-Ultrasonic motor, piezoelectric actuator, waterproof actuator, TR motor.

\section{INTRODUCTION}

The authors have been developing multi degree of freedom motor (translational and rotational motion in one joint, TR motor) by ultrasonic technology [1]-[3]. This motor has attractive features that is, TR movements independently or simultaneously, easy to make a micro motor and high controllability. It has high potential of usage in unconventional field such as medical device, space actuator and robotic actuator of outfield. In this research, the authors focus on the application in water and have improved it.

\section{DRIVE PRINCIPLE OF TR MOTOR}

TR motor is shown in Fig. 1. The stator has been fabricated as a rectangular metallic solid with a through-hole. Piezoelectric ceramics are pasted on each side of stator. The operator applies alternative voltage to the ceramics, the frequency of which is resonant. Three resonant vibration modes are used; one mode ( $\mathrm{R}$ mode) is for rotational movement and two modes (T1 and T2 mode) are combined for translational movement [4]-[6].

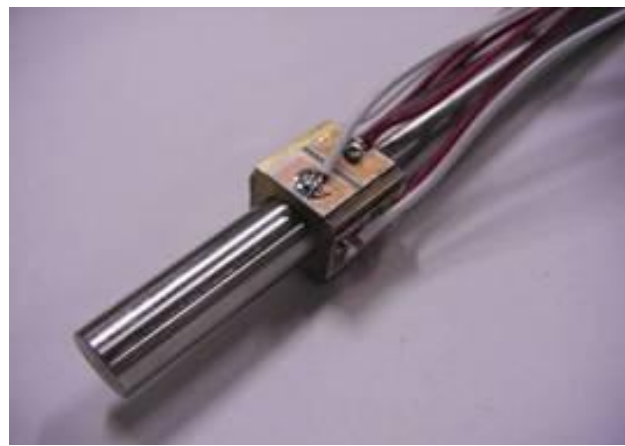

Fig. 1. TR motor.

Manuscript received January 30, 2017; revised March 20, 2017.

Shigeki Toyama and Uichi Nishizawa are with Tokyo University of Agriculture and Technology, Koganei, Tokyo, Japan (e-mail: toyama@cc.tuat.ac.jp,n-uichi@cc.tuat.ac.jp).
Applying voltage to the ceramics, the surface of the inner circle of the hole generates elastic vibrational that transfers energy to the shaft by frictional contact.

\section{A. Vibrational Mode for Rotation}

$\mathrm{R}$ mode is a vibrational mode characterized by three nodes around the surface of the hole's inner circle as shown in Fig. 2. It produces a traveling wave to go along the surface, at the top of which the frictional force is transmitted from the stator to the output shaft.

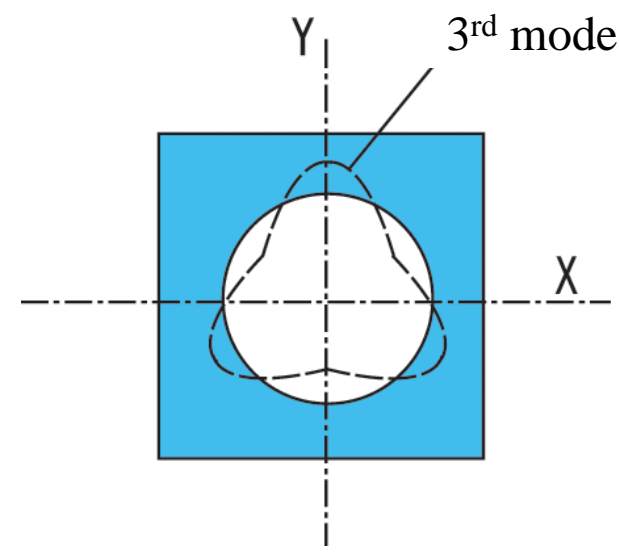

Fig. 2. Vibration mode for rotation.

\section{B. Vibrational Modes for Translation}

T1 and T2 modes are 1st and 2nd order axial modes of vibration as shown in Fig. 3. The TR motor uses the superposition of these two modes for translation. When stator is cubic shape, the T1 and T2 modes are excited by the same or very near frequencies. For this reason, when an operator has applied one frequency of voltage, two modes are generated and it produces translational movement.

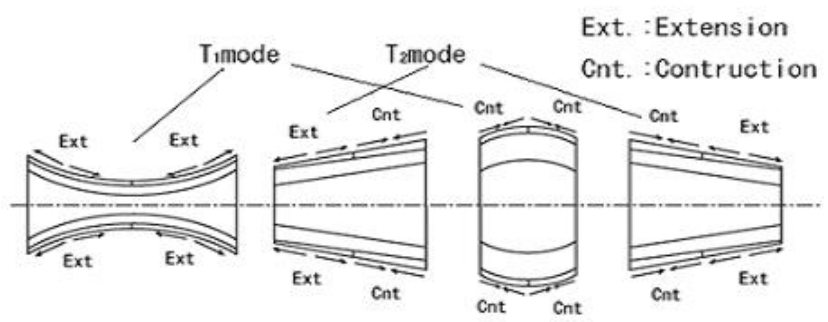

Fig. 3.Vibration mode for translation.

\section{Phase Difference Control}

There are two control parameters of the motor; frequencies and phase differences of the applied voltages. In this research, the frequencies should be set to the resonant ones to obtain best performance. The operator controls phase differences of the voltages and controls rotational speed and the direction (Fig. 4 and Table I). 


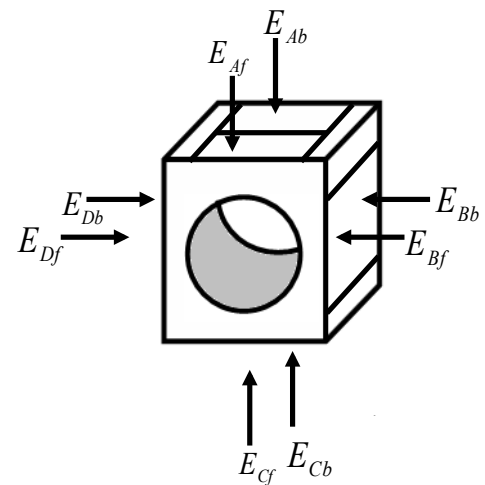

Fig. 4. Phase difference of applied voltage.

\begin{tabular}{l|l}
\multicolumn{1}{c}{ TABLE I: APPLIED VOLTAGE FOR TRANSLATION AND ROTATION } \\
\hline \hline & \multicolumn{1}{c}{ Applied voltage } \\
& $A$ : maximum applied voltage \\
& $f_{t}:$ resonant frequency, $t$ : time \\
\hline Translation & $E_{A f}=E_{B f}=E_{C f}=E_{D f}=A \sin \left(2 \pi f_{r} t\right)$ \\
& $E_{A b}=E_{B b}=E_{C b}=E_{D b}=A \sin \left(2 \pi f_{r} t\right)$ \\
\hline \multirow{2}{*}{ Rotation } & $E_{A b}=E_{A f}=A \sin \left(2 \pi f_{r} t\right)$ \\
& $E_{B b}=E_{B f}=A \cos \left(2 \pi f_{r} t\right)$ \\
& $E_{C b}=E_{C f}=-A \sin \left(2 \pi f_{r} t\right)$ \\
& $E_{D b}=E_{D f}=-A \sin \left(2 \pi f_{r} t\right)$ \\
\hline \hline
\end{tabular}

\section{WATERPROOF ULTRASONIC MOTOR}

The electrode of the piezoelectric ceramics is non-waterproof. In order to use in the water, electrode should be coated by water resist material. In this research the authors have applied three insulators: silicone rubber, poly vinyl resin (coating sprayer for electronic substrate) and epoxy putty (Fig. 5).

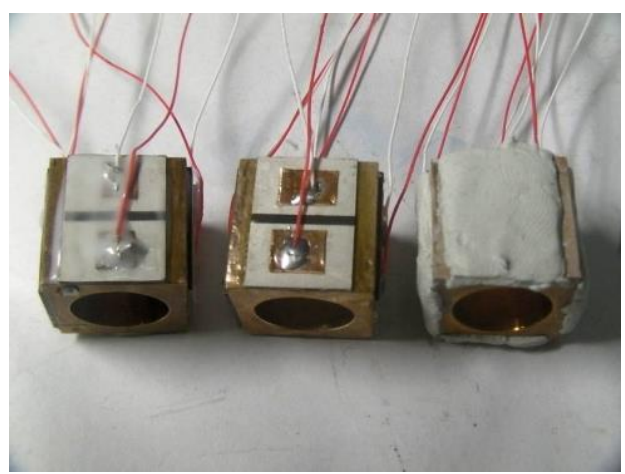

Fig. 5. TR motors with silicone rubber, polyvinyl resin and epoxy putty from the left.

Silicone rubber has half fluidity by short time's overheating and well gluing with metals. It has been used for sealant and protection and protective layer due to characteristics of heat resistance, waterproof and chemical resistance.

Poly vinyl resin has electrical insulation, which is widely used for coating electrical circuits to keep moisture resistance and insulation. The authors have sprayed it on the electrode twice every 20 minutes.
Epoxy putty has been widely used as gluing paste of two liquid mixing types. The main ingredient is epoxy resin which shows high gluing force, water resistance and easy to apply.

Since poly vinyl is spray type, the coating layer is thin. Silicone rubber and epoxy putty are pasted thick on the stators (Table II).

\begin{tabular}{l|r|r}
\multicolumn{2}{c}{ TABLE II: INSULANT THICKNESS } \\
\hline \hline \multirow{4}{*}{ Insulant } & Silicone rubber & Thickness [mm] \\
\hline & Poly vinyl resin & 0.20 \\
\cline { 2 - 3 } & & \\
& & 0.07 \\
\cline { 2 - 3 } & Epoxy putty & 0.88 \\
& & \\
\hline \hline
\end{tabular}

First, the authors have evaluated the waterproof type stators in air. The results are shown in TABLE III. It shows that maximum rotational velocity is reduced due to coating material to suppress the vibration.

TABLE III: COMPARISON OF THE VELOCITIES (RATIO OF WITH INSULANT / WITH NO INSULANT)

\begin{tabular}{l|l|c|c}
\hline \hline \multicolumn{2}{l|}{} & Rotation & Translation \\
\hline \multirow{4}{*}{ Insulant } & Silicone rubber & $43 \%$ & $52 \%$ \\
\cline { 2 - 4 } & Polyvinyl resin & $60 \%$ & $67 \%$ \\
& & & \\
\cline { 2 - 4 } & Epoxy putty & $47 \%$ & $66 \%$ \\
& & & \\
\hline \hline
\end{tabular}

Secondly, the authors have made experiments in water and observed no rotational or translational movement. This is because there is a very thin water film between the stator and the rotor and it causes no driving force transmission from the stator to the rotor. In order to prevent the water film, the authors have improved the outer shape of the rotor by knurled.

The knurled has irregularity on the surface of the rotor and it is expected to inhibit the water film and help keeping firm contact with each other. The knurled has two types: parallel and diagonal.

The authors have designed new type of the rotor as shown in Fig. 6.
(a)Normal shaft without knurled
(b)Diagonal knurled shaft (pitch $1.0 \mathrm{~mm}$ )
(c)Parallel knurled shaft (pitch $1.0 \mathrm{~mm}$ )
(d)Diagonal knurled shaft (pitch $0.8 \mathrm{~mm}$ )
(e)Parallel knurled shaft (pitch $0.8 \mathrm{~mm}$ )

Shaft's length $150 \mathrm{~mm}$, diameter $9.98 \mathrm{~mm}$, tolerance $\mathrm{h} 8$ 


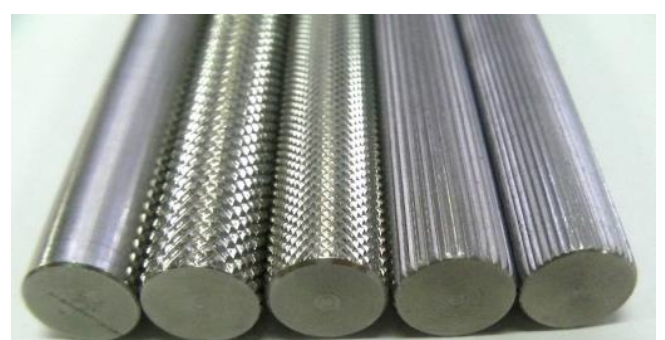

Fig. 6. Normal and knurl shaftstype. (a), (b),(c),(d), and(e) from the left.

\section{EXPERIMENTS IN WATER}

Before trying to drive it in water, the authors have evaluated the new shafts in the air. The results are shown Fig. 7. Each shaft shows the same characteristics of velocity in the air as normal shaft.

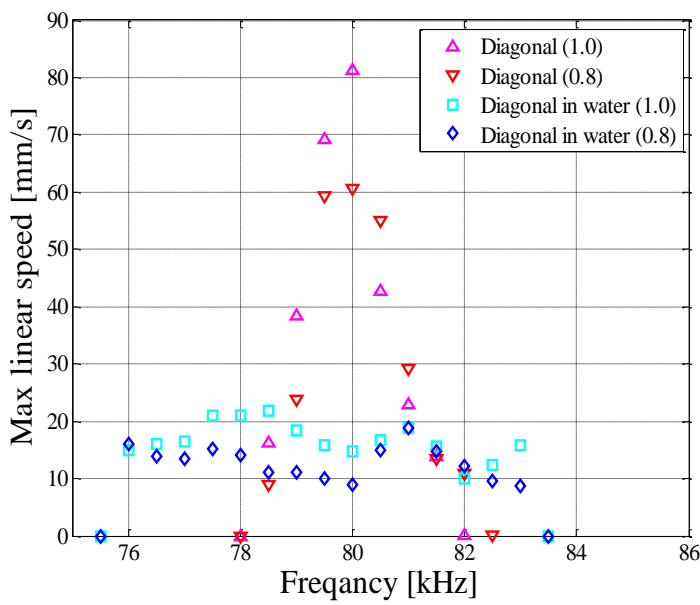

(a) Max linear speed.

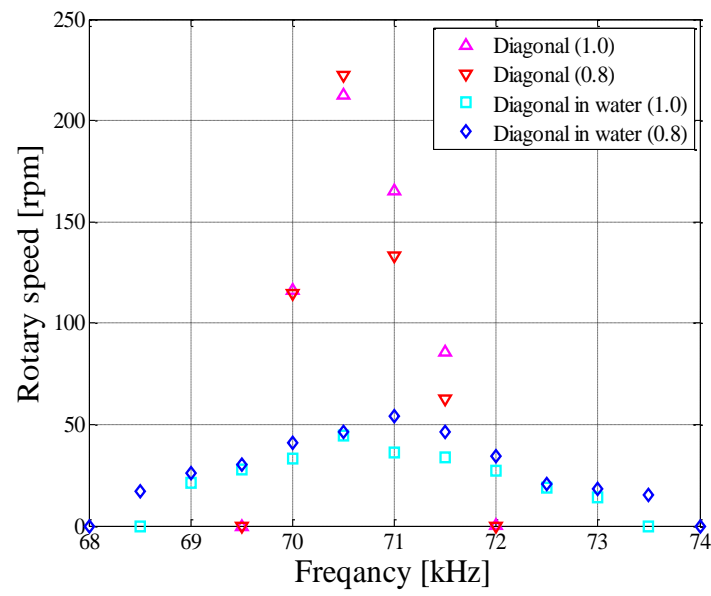

(b) Rotary speed.

Fig. 7. Frequency characteristics in water (Polyvinyl resin).

Third, the authors have evaluated these shafts (rotors) in water. In the experiment, the authors have obtained the results as follows.

1). The stator with epoxy putty cannot drive any types of shafts.

2). The parallel knurled shafts cannot be driven by any stators.

3). The stators with silicone rubber and polyvinyl resin can drive the diagonal knurled shafts.

Comparison of the velocity in the air and the water is shown in Table IV.
TABLE IV: COMPARISON OF THE VELOCITIES (RATIO OF IN THE WATER/ IN THE AIR)

\begin{tabular}{l|c|c|c}
\hline \hline \multirow{2}{*}{ Silicone rubber } & Knurl & Rotation & Translation \\
\cline { 2 - 4 } & Diagonal (Pitch 1.0) & $20 \%$ & $27 \%$ \\
& Diagonal (Pitch 0.8) & $21 \%$ & $31 \%$ \\
\hline \multirow{2}{*}{ Polyvinyl resin } & Diagonal (Pitch 1.0) & $25 \%$ & $34 \%$ \\
\cline { 2 - 4 } & Diagonal (Pitch 0.8) & $38 \%$ & $31 \%$ \\
\hline \hline
\end{tabular}

\section{CONCLUSIONS}

The authors have concluded as follows.

1) Applying silicone rubber and polyvinyl resin to the stators for waterproof and using diagonal knurled shaft, the authors can drive the TR motor in water successfully.

2) These TR motor can be driven in the air, but the velocity of the motors is reduced 20 percent comparing to that with no insulant.

\section{REFERENCES}

[1] S. Chen, B. Mulgrew, and P. M. Grant, "A clustering technique for digital communications channel equalization using radial basis function networks," IEEE Trans. on Neural Networks, vol. 4, pp. 570-578, July 1993.

[2] K. Masamune, et al., "Development of an MRI compatible needle insertion manipulator for stereotactic neurosurgery," Jounal Image Guided Surgery, vol. 1, pp. $242-247,1995$.

[3] T. Mashimo and S. Toyama, "Development of the translational and rotational piezoelectric actuator using a single stator (1st report)-Design of the stator by finite element method analysis," Journal of the Japan Society for Precision Engineering, vol. 74, no. 3, pp.292-297, 2008.

[4] P. A. M. Ferreira, "High-performance load-adaptive speed control for ultrasonic motors," IFAC, J. Control Engineering Practice, vol.6, no.1, pp. 1-10, 1998.

[5] M. Hoshina, T. Mashimo, N. Fukaya, O. Matsubara, and S. Toyama, "Spherical ultrasonic motor drive system for pipe inspection," Advanced Robotics, vol. 27, 2013.

[6] T. Mashimo and S. Toyama, "Vibration analysis of cubic rotary-linear piezoelectric actuator," IEEE Transactions on Ultrasonics, Ferroelectrics, and Frequency Control, vol. 58, pp. 844-847, 2011.

[7] T. Mashimo, S. Toyama, and H. Ishida, "Design and implementation of a spherical ultrasonic motor," IEEE Transactions on Ultrasonics, Ferroelectrics, and Frequency Control, vol. 56, pp. 2514-2521, 2009.

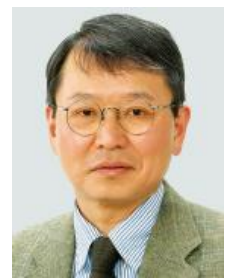

Shigeki Toyama received his Ph.D. degree in engineering from University of Tokyo, Tokyo, Japan, in 1981. Now he works at Tokyo University of Agriculture and Technology. His current research interests include robotics, actuator, and welfare technology.

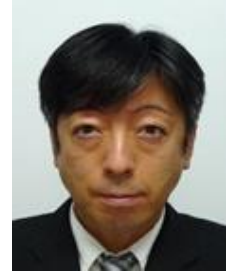

Uichi Nishizawa received his Ph.D. degree in engineering from Tokyo University of Agriculture and Technology, Tokyo, Japan, in 2008. Now he works at Tokyo University of Agriculture and Technology. His current research interests include robotics, aerospace engineering, and welfare technology. 